\title{
NMDA receptor action and spatial memory: The effects of MK-801 and D-cycloserine on rate of forgetting and initial discriminability
}

\author{
ANGELA C. RUSKE, DAVID N. HARPER, MICHAEL W. COLOMBO, and K. GEOFFREY WHITE \\ University of Otago, Dunedin, New Zealand
}

\begin{abstract}
The NMDA receptor antagonist MK-801 impairs performance of nonhumans in memory tasks. The NMDA receptor agonist D-cycloserine (DCS) facilitates learning and memory. In the present study, the effects of MK-801 and DCS on rats' performance in a delayed matching-to-position task were examined. Proportion of correct matching responses decreased in a dose-dependent manner after doses of 0.05 and $0.08 \mathrm{mg} / \mathrm{kg}$ of MK-801. There was no effect of DCS at dose levels of 1 and $3 \mathrm{mg} / \mathrm{kg}$ at short delays, but accuracy was facilitated at the dose level of $3 \mathrm{mg} / \mathrm{kg}$ at the longest delay. By fitting a negative exponential function to measures of discriminability, independent measures of initial discriminability and rate of forgetting were derived. Administration of MK- 801 reduced initial discriminability but not rate of forgetting. Administration of DCS did not improve initial discriminability and did not affect rate of forgetting. These data suggest that MK-801 affects memory by disrupting processes relating to attention or encoding of the stimulus.
\end{abstract}

There is increasing evidence that the neural mechanisms involved in memory depend on the action of the $N$-methylD-aspartate (NMDA) receptor, an excitatory amino acid receptor subtype (Collingridge \& Bliss, 1987; Monahan, Handelmann, Hood, \& Cordi, 1989). The involvement of NMDA receptor action in learning and memory is supported by evidence showing that drugs that affect NMDA receptor action also disrupt memory and learning (Abraham, 1988). A mechanism associated with NMDA receptor action is long-term potentiation (LTP), a phenomenon resulting in a lasting increase in synaptic efficacy as the result of brief high-frequency activity of input fibers (Abraham, 1988). This activity-dependent change in synaptic efficacy has been suggested to underly the physiological basis of memory storage in the brain (Collingridge \& Bliss, 1987). The NMDA receptor contains a number of binding sites that are capable of influencing LTP induction and behavior (Foster \& Kemp, 1989). NMDA receptors are found in high density in the hippocampus (Collingridge, Kehl, \& McLennan, 1983), a structure believed to be involved in spatial and contextual memory (Barnes, 1988).

The administration of NMDA receptor antagonists has been shown to cause learning and memory deficits, particularly in spatial-oriented memory tasks. Davis, Butcher, and Morris (1992) suggest that there is a high correlation between LTP induction and spatial learning. MK-801 $([+\}-$ 10,11-dihydro-5-methyl-5H-dibenzo[ad] cycloheptene5,10 imine), a noncompetitive NMDA receptor antagonist, not only blocks the induction of LTP in vivo (Abraham \&

Correspondence should be addressed to A. Ruske, Department of Psychology, University of Otago, Dunedin, New Zealand (e-mail: syco578@otago.ac.nz).
Mason, 1988) and in vitro (Wong et al., 1986) but impairs performance on spatial memory tasks. For example, Morris (1989) found impairment in a spatial memory task and blockade of LTP induction with the application of AP5 (a NMDA receptor antagonist that competes for binding at the L-glutamate recognition site). Butelman (1988) administered MK-801 to rats trained on an eight-arm radial maze task and found that efficiency in the task decreased in a dose-related manner. Similarly, Caramanos and Shapiro (1994) examined the effects of MK-801 on spatial working memory and reference memory in rats. They found that daily injections of MK-801 during testing impaired performance. They also found that reversal learning but not working memory performance was impaired following administration of MK-801. These contrasting effects of MK-801 on performance were believed to be due to the result of training duration (where well-trained animals were less sensitive to the effects of NMDA antagonists), the dose level of the drug, and the amount of familiarity the animal had with its environment.

Recently, attention has focused on the ability of NMDA receptor agonists to facilitate learning and memory. Drugs that act as agonists at the NMDA receptor complex may also facilitate cognition (possibly through their ability to enhance or prolong the induction of LTP). Glutamic acid (an excitatory amino acid) administered through intracerebroventricular injections (i.c.v.) enhanced learning in rats on a maze and shock avoidance task (Flood, Baker, \& Davis, 1990). Milacemide, a drug that increases brain glycine levels, also enhances the retention of a passive avoidance task in rats and reverses deficits induced by scopolamine (a muscarinic antagonist) and AP7 (NMDA antagonist) in spontaneous alternation (Handelmann, Nevins, Mueller, Arnolde, \& Cordi, 1989). D-cycloserine (DCS), a proposed 
novel cognitive enhancer, is a partial glycine agonist known to cross the blood-brain barrier. Monahan et al. (1989) found that rats' performance in passive avoidance and T-maze task was improved with administration of DCS. Baxter et al. (1994) examined the behavioral effects of DCS on cognitive deficits in young and old rats using a place discrimination and repeated acquisition task in the water maze. They found that DCS improved age-related deficits in both tasks.

The present study was concerned with the effects of MK-801 and DCS on the performance of rats in a delayed matching-to-position (DMTP) procedure. Given the proposed role of the hippocampus in spatial memory and the high density of NMDA receptors in that region, it was important to use a procedure that was dependent on hippocampal function. Hippocampal lesion studies have shown the DMTP procedure is sensitive to changes in hippocampal function (e.g., Dunnett, 1985; Harper, McLean, \& Dalrymple-Alford, 1994). The other advantage of this procedure was that a negative exponential function could be fitted to discriminability values at different retention intervals, enabling independent measures of rate of forgetting and initial discriminability to be derived. This analytical procedure has been adopted by a number of studies examining the specific effect of drug action on memory (e.g., Watson \& Blampied, 1989; Watson \& White, 1994). Given prior evidence that DCS enhances memory through its action on the NMDA receptor, it was expected that DCS would facilitate DMTP performance. Conversely, because MK-801 blocks NMDA receptor action, it was predicted that this drug would impair performance. By fitting a negative exponential function to discriminability values, we were able to determine what aspects of performance were disrupted as the result of drug administration-that is, whether changes in performance were due to changes in initial discriminability or rate of forgetting.

\section{METHOD}

\section{Subjects}

The subjects were 10 male Sprague-Dawley rats, with 1 month's experience in the present delayed matching-to-position procedure, $20-24$ months of age and weighing between 350 and $420 \mathrm{~g}$. The rats were weighed daily and maintained at $85 \%( \pm 10 \mathrm{~g})$ of their freefeeding weight, with water available at all times in their individual home cages. They were kept in a room lit by artificial light on a 12:12-h light:dark cycle. Room temperature was maintained between $20^{\circ}$ and $25^{\circ} \mathrm{C}$. Experimental sessions were conducted daily between 8 and 9 a.m. for each rat, unless the rat's weight was outside the prescribed range.

\section{Apparatus}

Each of 10 Campden Instruments experimental chambers, $25 \mathrm{~cm}$ wide, $23 \mathrm{~cm}$ deep, and $20 \mathrm{~cm}$ high, was enclosed in a light- and soundattenuating enclosure. Each chamber was fitted with two retractable levers situated $2.5 \mathrm{~cm}$ on either side of a central food dipper, which had a hinged clear Plexiglas door. Chamber illumination was provided by a $2.8-W$ houselight situated centrally on the chamber ceiling. Above each lever were 2.4 -W lights, which were illuminated for $0.2 \mathrm{sec}$ each time the levers were pressed. A 2.4-W light was situated $7 \mathrm{~cm}$ above the Plexiglas door and was lit during reinforcer delivery. Reinforcement was provided by a dipper that provided $2.5 \mathrm{ml}$ of sweetened condensed milk diluted with an equal quantity of water. Experimental events were controlled and recorded by individual microcomputers and associated SPIDER software and interfacing manufactured by Paul Fray Ltd.

\section{Behavioral Procedure}

Daily experimental sessions consisted of 65 trials. The first trial at the beginning of each session did not contribute to data analysis. Each trial began with the insertion of either the left or the right lever into the experimental chamber. The third leverpress retracted the lever, and the first nosepoke through the Plexiglas door initiated the retention interval. During the retention interval, the chamber was darkened and all responses were ineffective. Comparison stimuli (left and right levers) were inserted into the experimental chamber following the completion of the retention interval. A single correct response retracted both levers and produced a 2 -sec access to sweetened condensed milk, followed by an intertrial interval (ITI) of $5 \mathrm{sec}$. Incorrect responses resulted in a $2-\mathrm{sec}$ blackout followed by a 5 -sec ITI. The order of left and right sample stimuli was randomized within each session. Each type of trial was tested an equal number of times with 1-, 4-, 12-, and 24-sec retention intervals.

Fifteen sessions of baseline training in the above procedure were preceded by five sessions of training in the same procedure with shorter delay intervals $(0.2,1,2$, and $4 \mathrm{sec})$. Drug and vehicle administration and additional baseline training were conducted over 98 sessions following the initial baseline training. Following the initial 15-day baseline training, the rats were randomly divided into two groups of 5 . One group received MK-801 plus vehicle control injections, and the other group was administered DCS plus vehicle control injections. No rat received both drugs, but all rats within each group received both dose levels of one drug and vehicle control.

\section{Drug Administration}

MK-801 and DCS, obtained from commercial suppliers, were diluted to their required concentrations using physiological saline and distilled water, respectively. The doses used were 0.05 and $0.08 \mathrm{mg} / \mathrm{kg}$ of MK-801 and 1 and $3 \mathrm{mg} / \mathrm{kg}$ of DCS. The two doses plus vehicle control of physiological saline (designated as $0 \mathrm{mg} / \mathrm{kg}$ ) were administered in the following orders: MK-801, 0, 0.05, 0.05 . $0.08,0.08,0.05,0,0.05,0.08,0.08,0,0,0,0.08,0,0.05,0.05,0.08$; DCS, $0,1,3,3,1,0,3,1,0,1,3,3,0,0,0,3,1,1$. The order of administration within each group was the same for each rat. Doses were injected intraperitoneally at a constant volume of $1 \mathrm{ml} / \mathrm{kg}$ $10 \mathrm{~min}$ before the beginning of the experimental session. Sessions with drug or vehicle were separated by 2 days of baseline training. Each rat received 6 sessions of training for each dose level, including vehicle control, making a total of 18 drug sessions. By the end of the experiment, each rat had completed 98 sessions in total since initial baseline training.

\section{Data Analysis}

Total correct and error matching responses at each of the four retention intervals were summed over the 6 sessions conducted for each dose level of drug, including saline injections (individual analysis), and over subjects in each group (pooled analysis). Proportion correct data were calculated by dividing correct responses by total number of responses (correct plus error) for individual and pooled data. Estimates of discriminability at each delay were derived from proportion correct responses according to

$$
\operatorname{logit}(p)=\log [p /(1-p)]
$$

where $p$ is proportion correct. Logit $(p)$ was chosen as the measure of discriminability because when response bias is minimal, as was the case for the present data, it has properties similar to those of traditional discriminability measures, such as $d^{\prime}$. Additionally, it is not bounded at 1.0 , as is percent correct, and accordingly is not constrained by a ceiling effect. 
Proportion correct and logit $(p)$ measures for each group were submitted to a repeated measures analysis of variance (ANOVA), with dose and retention interval as the independent variables. A criterion of $p<.05$ was required for significance.

The negative exponential equation (Equation 2 below) suggested by White and Harper (in press) was fitted to individual and pooled discriminability measures, plotted as a function of programmed delays. Actual delays, however, are determined by the latency between the third response on either lever (left or right sample) and the first nosepoke response that initiated the delay. In the present experiment, these latencies were not recorded. Our analyses of the data from a previous experiment where latencies were recorded (Kirk, White, \& McNaughton, 1988) showed that the discriminability values fell on the same forgetting functions, whether programmed or actual delay values were used. Furthermore, the parameter values for functions fitted to data plotted against actual and programmed delays were practically identical except for a small decrease in the parameter value for initial discriminability with programmed delays. We therefore concluded that the use of programmed delays in our data analysis was justified.

$$
y=a * \exp (-b * \sqrt{t})
$$

In Equation 2, $y$ is the measure of discriminability at delay $t$, and the parameters $a$ and $b$ afford independent measures of remembering (White, 1985). The $y$-intercept $a$ describes discriminability at zero delay ("initial discriminability"), and $b$ (the slope of the function) describes the rate of forgetting. Factors affecting $a$ contribute to the encoding of the sample stimuli and involve attentional or perceptual processes. The slope of the function or rate of forgetting $(b)$ is affected by factors that interfere with retrieval and rehearsal mechanisms (White, 1985).

\section{RESULTS}

To determine baseline performance over the course of the experiment, percent correct matching responses were averaged over each of the single days immediately preceding each drug administration day. Mean percent correct were $0.990,0.984,0.934$, and 0.885 for the $1-, 4-, 12-$, and 24-sec retention intervals, respectively. This high level of performance across all retention intervals shows that the baseline was maintained over the experiment and that the 2-day washout period used was sufficient to eliminate carryover effects from previous drug administration days.

Figure 1 shows proportion correct responses for averaged group data as a function of retention interval for MK801- and DCS-treated rats. There was only a slight decrease in correct matching responses from saline at the $0.05-\mathrm{mg} / \mathrm{kg}$ dose level of MK-801, but there was a clear decrease in performance relative to that from saline across all delays and for all rats at the $0.08-\mathrm{mg} / \mathrm{kg}$ dose level. A repeated measures ANOVA revealed a significant effect of dose on performance $[F(2,8)=34.51]$ and delay $[F(3,12)=$ 15.863 ], as well as a significant dose $\times$ delay interaction $[F(6,24)=3.642]$. The effect of DCS on proportion correct responses was not significant $[F(2,8)=1.03]$, possibly because of the high level of performance at each retention interval in the saline condition. While mean group data showed a trend toward a dose-dependent improvement in performance at the longest retention interval $(24 \mathrm{sec})$, this was not a consistent finding for all rats.

Figure 2 shows discriminability (logit $p$ ) as a function of retention interval for MK-801 - and DCS-treated rats.

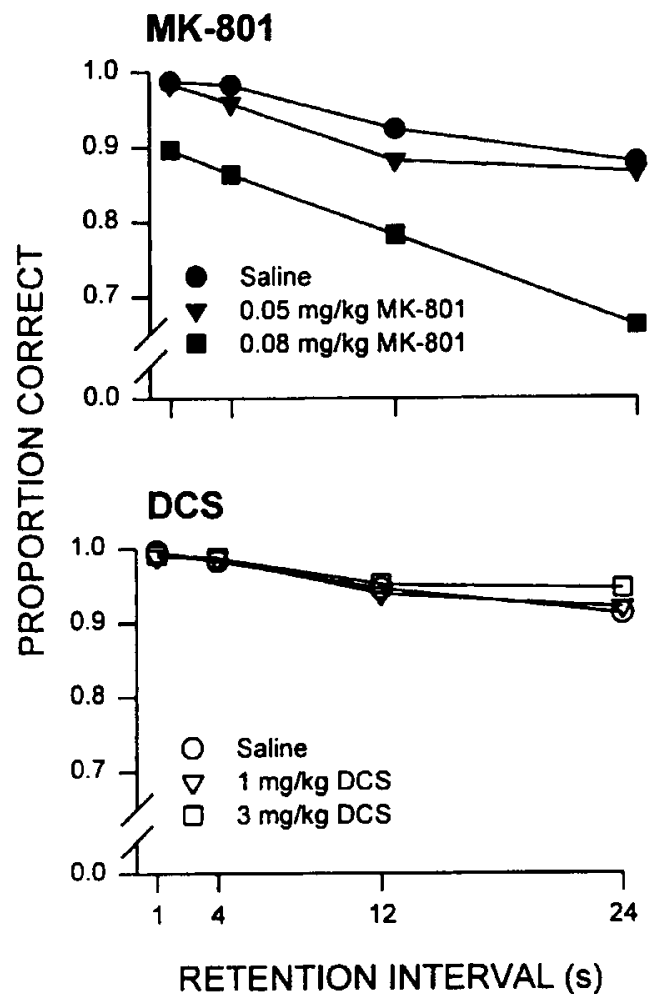

Figure 1. Proportion correct responses for averaged group data as a function of retention interval for MK-801 (top panel) and DCS (bottom panel) conditions.

There was a systematic decrease in performance from saline for each of the two dose levels of MK-801. The largest effect on performance occurred at the $0.08-\mathrm{mg} / \mathrm{kg}$ dose level, where discriminability decreased systematically as a function of increasing retention interval for all rats. There were significant effects of dose $[F(2,8)=40.18]$ and delay $[F(3,12)=28.45]$, as well as a significant dose $\times$ delay interaction $[F(6,24)=5.20]$. There was little systematic variation for either dose of $\operatorname{DCS}[F(2,8)=2.84]$, but a paired $t$ test conducted at the 24 -sec retention interval revealed a significant difference between saline and the $3-\mathrm{mg} / \mathrm{kg}$ dose level $[t(4)=2.85, p<.05]$.

Equation 2 described performance very well. Least squares regression fits of the negative exponential to individual data yielded mean squared error terms that ranged from 0.001 to 0.195 , with a mean of 0.043 . The mean proportion of variance accounted for by the best-fitting functions was 0.807 . There was no difference between the mean proportion of variance accounted for by functions fitted to the different data sets for the two drugs.

Figure 3 summarizes changes in $a$ resulting from MK801 and DCS administration. There was a dose-dependent decrease in $a$ for all rats in the MK-801 condition $[F(2,8)=$ $90.25]$. Initial discriminability $(a)$ for pooled data decreased from 2.411 (saline) to 2.218 at the $0.05-\mathrm{mg} / \mathrm{kg}$ dose level to 1.260 at the $0.08-\mathrm{mg} / \mathrm{kg}$ dose level. There was no significant effect of DCS on initial discriminability $[F(2,8)=1.24]$. There was a small decrease in $a$ from saline 
MK-801
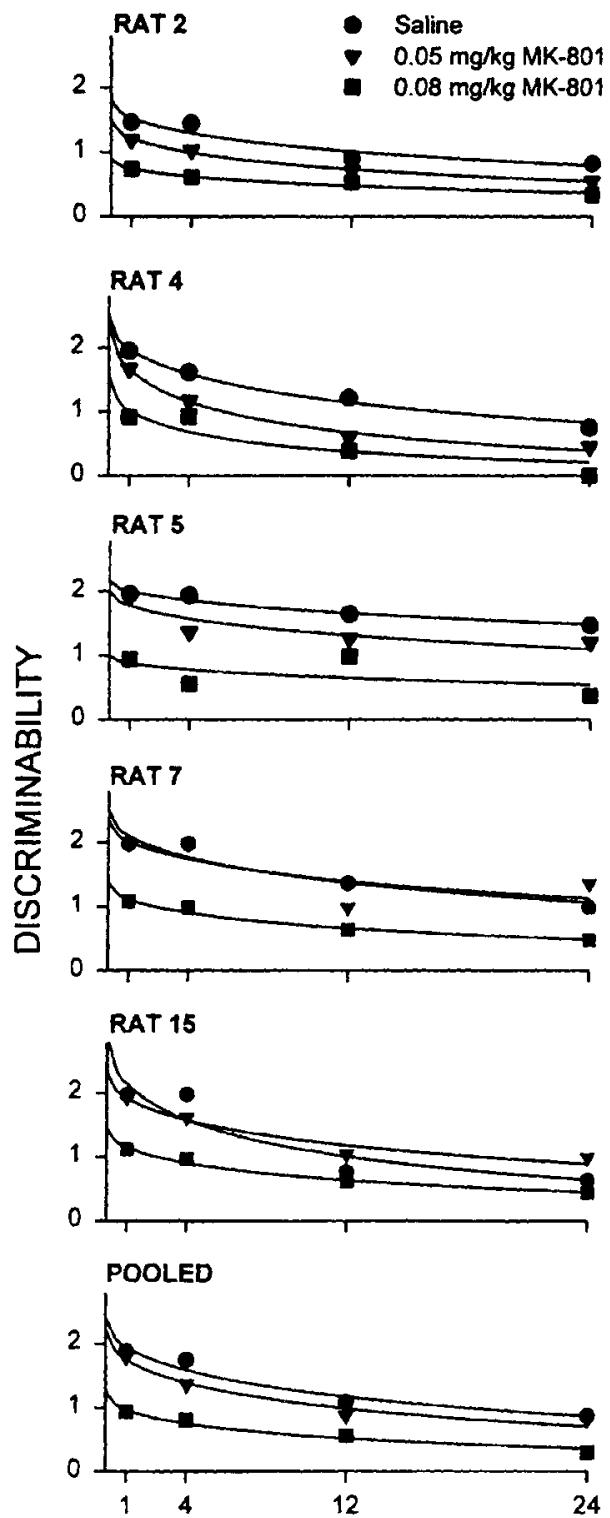

DCS
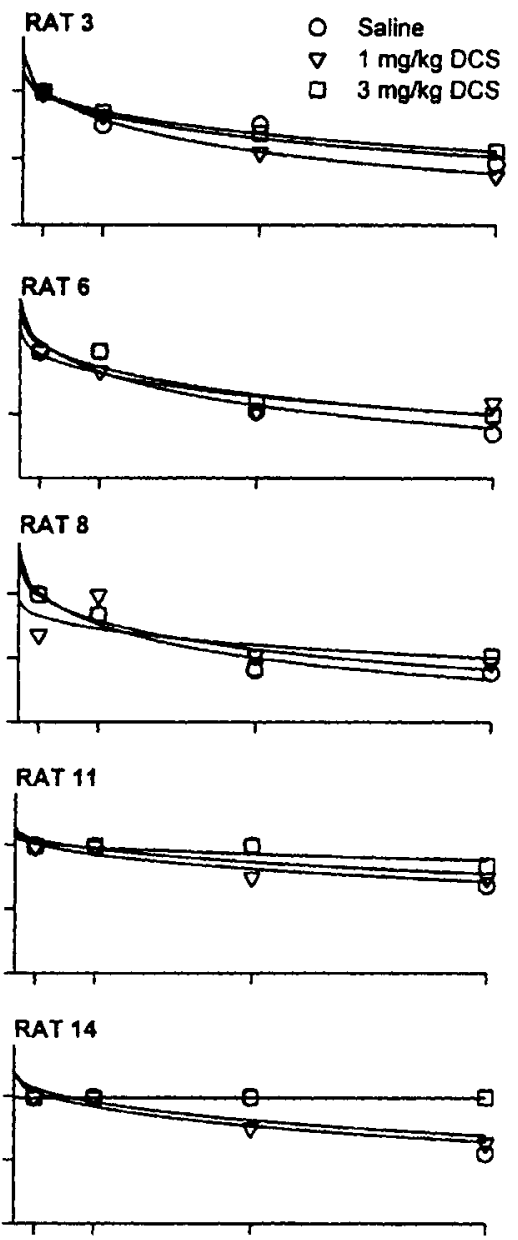

POOLED

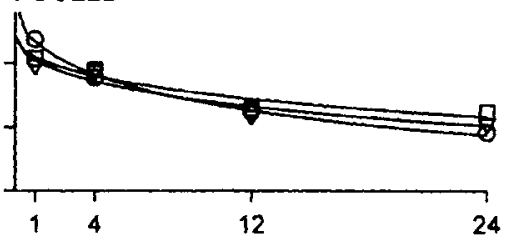

RETENTION INTERVAL (s)

Figure 2. Discriminability [Logit ( $p$ )] as a function of retention interval for individual and pooled data for MK-801-treated rats (left) and DCS-treated rats (right).

(2.945), however, for 4 of the 5 rats $(2.446$ and 2.440 for the 1 - and $3-\mathrm{mg} / \mathrm{kg}$ dose level, respectively). Pooled data showed little difference in initial discriminability for the 1 - and $3-\mathrm{mg} / \mathrm{kg}$ dose levels, both of which were lower than the saline condition.

Figure 4 shows changes in rate of forgetting $(b)$ for MK-801 - and DCS-treated rats. Relative to that for saline, there was an increase in the rate of forgetting at the 0.05$\mathrm{mg} / \mathrm{kg}$ dose level of MK-801, but this was only apparent for 3 of the 5 rats. The effect was more noticeable at the 0.08 $\mathrm{mg} / \mathrm{kg}$ dose level (an increase for 4 of 5 rats), but there was no significant effect of dose on rate of forgetting overall $[F(2,8)=1.14]$. There were small decreases in $b$ for 3 rats at the $1-\mathrm{mg} / \mathrm{kg}$ dose level of DCS $(0.236$ for saline, 0.178 for $1 \mathrm{mg} / \mathrm{kg}$ ), with a further reduction in $b$ occurring at the higher dose of $3 \mathrm{mg} / \mathrm{kg}(b=0.152)$. There was a trend toward a dose-dependent decrease in rate of forgetting for 3 rats, but this was not statistically significant for the group $[F(2,8)=1.41]$.

\section{DISCUSSION}

The present results show that MK-801 produced dosedependent decreases in $a$ (initial discriminability) at doses of 0.05 and $0.08 \mathrm{mg} / \mathrm{kg}$, suggesting that initial discriminability was sensitive to the effects of the drug. Its effect 
MK-801
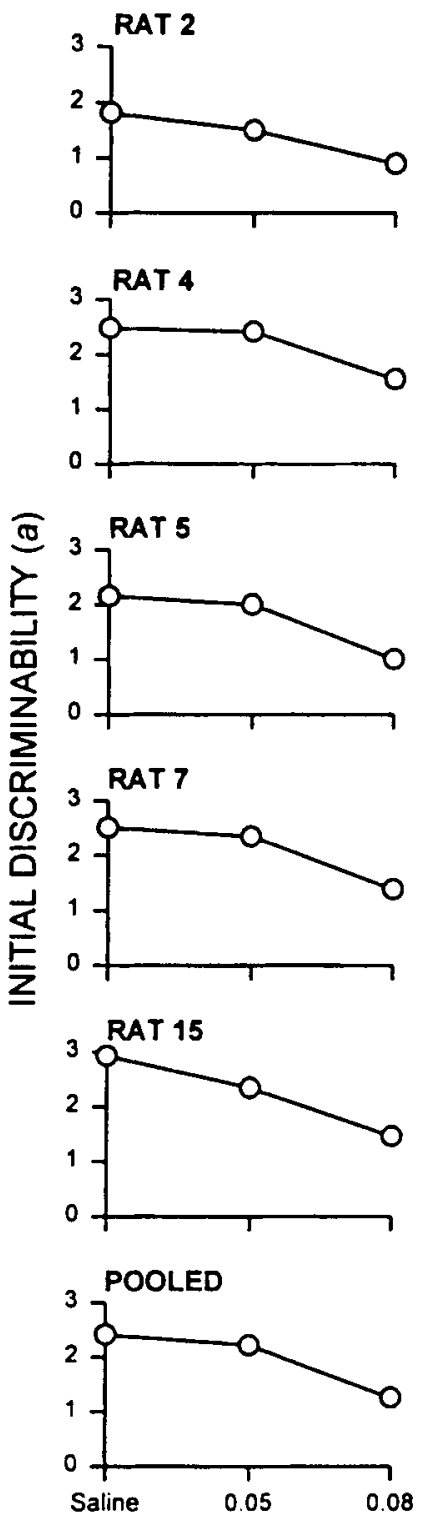

DOSE $(\mathrm{mg} / \mathrm{kg})$

Figure 3. Initial discriminability (a) plotted as a function of dose level for individual and pooled data for MK-801-treated rats (left panel) and DCS-treated rats (right panel).

on the rate of forgetting parameter $(b)$, however, was less consistent, and while pooled data showed the expected trend of a dose-dependent increase in $b$, this effect was not significant. Because the drug had a strong effect on factors affecting the initial discriminability of the task, it seems that disruption in performance was due to the fact that the drug was affecting attentional processes relating to the encoding or perception of the stimuli. That is, NMDA receptor blockade disrupted performance by affecting encoding or perceptual processes, not by disrupting rate of forgetting. This conclusion is consistent with a number of stud-

ies that have failed to find delay-dependent deficits on working memory produced by MK-801 administration (Caramanos \& Shapiro, 1994; Shapiro \& Caramanos, 1990; Shapiro \& O'Connor, 1992; Tonkiss \& Rawlings, 1991). Tan, Kirk, Abraham, and McNaughton (1989) observed a decrease in the initial discriminability parameter for rats in a delayed conditional discrimination task with $0.33 \mathrm{mg} / \mathrm{kg}$ of MK-801, and they also observed an increase in the rate of forgetting, but not in a dose-related manner.

Given that Tan et al. (1989) found the threshold dose level of MK-801 effective in blocking LTP in the hippo-

MK-801
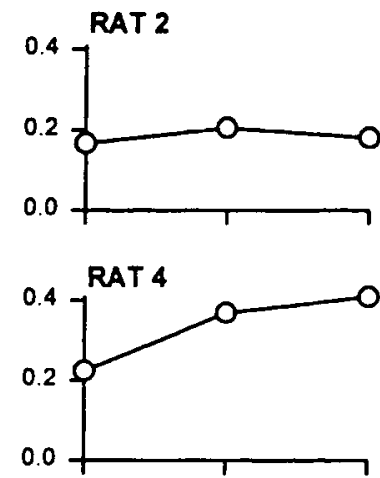

RAT 5

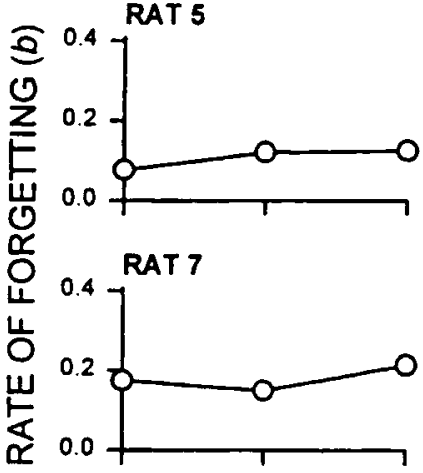

RAT 15
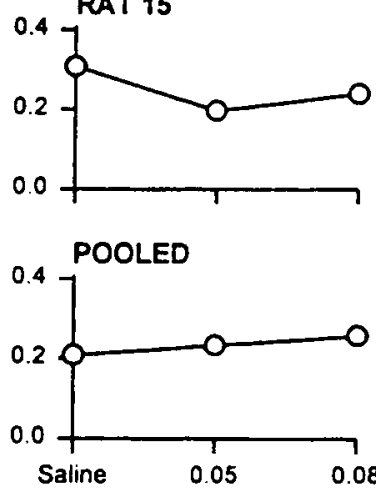

DOSE (mg/kg)
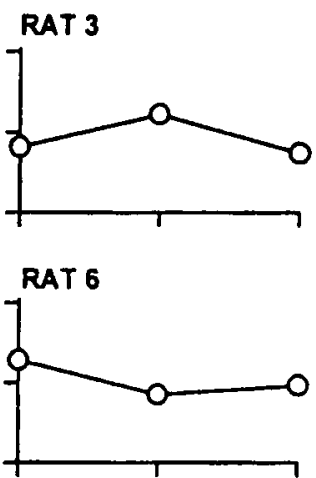

RAT 8

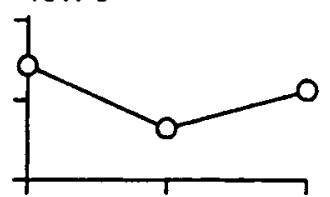

RAT 11

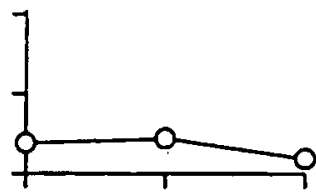

RAT 14

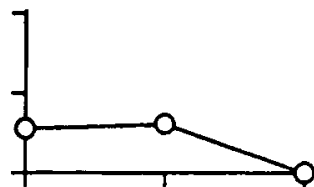

POOLED

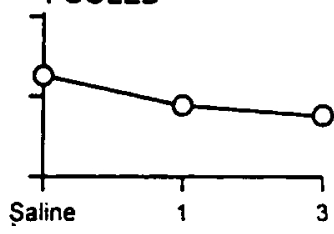

Figure 4. Rate of forgetting $(b)$ as a function of dose level for individual and pooled data for MK-801-treated rats (left panel) and DCS-treated rats (right panel). 
campus to be close to $0.1 \mathrm{mg} / \mathrm{kg}$, and given that aged rats show greater sensitivity to drugs acting on NMDA receptors in the hippocampus due to a compensatory mechanism that accounts for age-related decreases in NMDA receptors in that region (Barnes, 1994), it is possible that the dose level of $0.08 \mathrm{mg} / \mathrm{kg}$ could have blocked LTP in the hippocampus. However, it is not known whether the disruption in performance associated with MK-801 administration was due to blockade of hippocampal LTP or the blockade of NMDA receptor action elsewhere in the brain (which is quite conceivable given the route of administration).

Initial discriminability parameters $(a)$ for rats in the DCS group were similar for the 1 - and $3-\mathrm{mg} / \mathrm{kg}$ dose level conditions. And although both were lower than the saline condition, raising the possibility that the drug may have affected processes relating to encoding of the stimuli, there was no significant effect of DCS on initial discriminability. While there was a trend toward a dose-dependent decrease in rate of forgetting (which was reflected by an increase in performance at the 24 -sec retention interval), this was not significant. We predicted that DCS would facilitate memory (possibly due to its agonistic action at the glycine binding site on the NMDA receptor complex); this was true at the longest retention interval, but it was not apparent at the shorter delays.

It is unlikely that the failure of DCS to enhance performance was due to the use of inappropriate dose levels. Dose-response studies show that DCS has an inverted-U shape function, where very low or very high dose levels impair performance. Monahan et al. (1989) found that $3 \mathrm{mg} / \mathrm{kg}$ of DCS had a greater facilitatory effect on memory than did $0.03 \mathrm{mg} / \mathrm{kg}, 0.3 \mathrm{mg} / \mathrm{kg}$, and the higher dose of $10 \mathrm{mg} / \mathrm{kg}$. One possibility may be that the postinjection period before the rats began each session was not long enough for the drug to be completely absorbed, and therefore the "true" effect of the drug was not measured. Baxter et al. (1994) injected DCS at least $30 \mathrm{~min}$ prior to testing, whereas the present study used only a $10-$ min postinjection period before experimental testing began.

Another plausible explanation for these findings is that they may have been due to the high level of performance obtained in the saline condition. This may have produced a ceiling effect, therefore masking the facilitatory effect of the drug. This would explain the significant increase in performance at the longest retention interval.

A final possibility that must be considered is that DCS may not be efficient in improving certain memory-related tasks. Although there are a few studies that show improvements in cognitive ability as the result of DCS administration (e.g., Baxter, 1994; Monahan et al., 1989), there are a number of studies that have failed to report any improvements. For example, DCS was tested on its ability to reverse cognitive impairments induced by scopolamine (cholinergic-muscarinic antagonist) and phencyclidine (PCP, a noncompetitive NMDA antagonist) in primates (Rupniak, Duchnowski, Tye, Cook, \& Iversen, 1992). The results indicated no evidence of a dose-related improvement in the visuospatial memory task employed by these researchers. These findings are in accordance with a study by Moerschbaecher, Berthold, Stevens, Lamotte, and Pierson (1989), who failed to find a reversal of behavioral effects elicited by PCP when rats were injected with DCS.

This research contributes to previous work in this area because it incorporates the use of the negative exponential function, which quantifies the forgetting function (White, 1985). Several drug studies have employed this method to analyze their data (e.g., Melia, Koob, \& Ehlers, 1990; Watson \& Blampied, 1989; Watson \& White, 1994) and have shown that it has the ability to afford independent measures of remembering and to examine the sensitivity of these parameters to different drug effects. Much of the research investigating the behavioral changes associated with NMDA receptor action has been concerned with escape latencies or performance during the initial acquisition of the task. The present study provides evidence to suggest that NMDA receptor action is necessary for the efficient encoding of stimuli (whether this was the result of changes in LTP induction, however, is not known). The effect of DCS may be more apparent in tasks where the animals are more cognitively challenged. This could be achieved by examining the ability of DCS to reverse cognitive impairments associated with administration of NMDA receptor antagonists, such as MK-801.

\section{REFERENCES}

ABraham, W. C. (1988). Long-term potentiation as a possible associative memory mechanism in the brain. New Zealand Journal of Psychology, 17, 49-57.

Abraham, W. C., \& Mason, S. E. (1988). Effects of the NMDA receptor antagonists CPP and MK-801 on hippocampal field potentials in long-term potentiation in urethane anaesthetized rats. Brain Research, 462, 40-46.

BARNES, C. A. (1988). Spatial learning and memory processes: The search for their neurobiological mechanisms in the rat. Trends in Neurosciences, 11, 163-169.

BARNES, C. A. (1994). Normal aging: Regionally specific changes in hippocampal synaptic transmission. Trends in Neurosciences, 17, 13-18.

Baxter, M. G., Lanthorn, T. H., Frick, K. M., Golski, S., Wan, R., \& OLTON, D. S. (1994). D-Cycloserine, a novel cognitive enhancer, improves spatial memory in aged rats. Neurobiology of Aging, 15, 207-213.

Butelman, E. (1988). A novel NMDA antagonist, MK-801, impairs performance in hippocampal-dependent spatial learning task. Pharmacology, Biochemistry \& Behavior, 34, 13-16.

Caramanos, Z., \& Shapiro, M. L. (1994). Spatial memory and $N$ methyl-D-aspartate receptor antagonists APV and MK-801: Memory impairments depend on familiarity with the environment, drug dose, and training duration. Behavioral Neuroscience, 108, 30-43.

Collingridge, G. L., \& Bliss, T. V. P. (1987). NMDA receptors-Their role in long-term potentiation. Trends in Neurosciences, 10, 288-293.

Collingridge, G. L., Kehl, S. J., \& McLennan, H. (1983). Excitatory amino acids in synaptic transmission in the Schaffer collateralcommissural pathway of the rat hippocampus. Journal of Physiology, 334, 33-46.

Davis, S., Butcher, S. P., \& Morris, R. G. M. (1992). The NMDA receptor antagonist D-2-amino-5-phosphonopentanoate (D-APV) impairs spatial learning and LTP in vivo at intracerebral concentrations comparable to those that block LTP in vitro. Journal of Neuroscience, 12, $21-34$

Dunnett, S. B. (1985). Comparative effects of cholinergic drugs and lesions of nucleus basalis or fimbria-fornix on delayed matching in rats. Psychopharmacology, 87, 357-363. 
FloOD, J. F., BAKER, M. L., \& DAvIS, J. L. (1990). Modulation of memory processing by glutamic acid receptor agonists and antagonists Brain Research, 521, 197-202.

Foster, A. C., \& KeMP, J. A. (1989). Glycine maintains excitement. Nature, 338, 377-378

Handlemann, G. E., Nevins, M. E., Mueller, L. L., Arnolde, S. M., \& CORDI, A. A. (1989). Milacemide, a glycine prodrug, enhances performance of learning tasks in normal and amnestic rodents. Pharmacology, Biochemistry \& Behavior, 34, 823-828.

Harper, D. N., Mclean, A. P., \& Dalrymple-Alford, J. C. (1994). The effect of medial septum or mammilary body lesions on forgetting in rats. Behavioral Neuroscience, 108, 691-702.

Kirk, R. C., White, K. G., \& McNaughton, N. (1988). Low dose scopolamine affects discriminability but not rate of forgetting in delayed conditional discrimination. Psychopharmacology, 96, 541-546.

Melia, K. F., KoOB, G. F., \& Ehlers, C. L. (1990). Ethanol effects on delayed spatial matching as modeled by a negative exponential forgetting function. Psychopharmacology, 102, 391-398.

Moerschbaecher, J. M., Berthold, C. W., Stevens, P., Lamotte, L., \& PiERSON, M. (1989). Effects of excitatory amino acids on acquisition, retention and performance. Pharmacologv. Biochemistry \& Behavior, 32, 1080

Monahan, J. B., Handelmann, G. E., Hood, W. F., \& Cordi, A. A. (1989). D-Cycloserine, a positive modulator of the $N$-methyl-D-aspartate receptor, enhances performance of learning tasks in rats. Pharmacologv: Biochemistry \& Behavior, 34, 649-653.

Morris, R. G. M. (1989). Synaptic plasticity and learning: Selective impairment of learning in rats and blockade of long-term potentiation in vivo by the $N$-methyl-D-aspartate receptor antagonist AP5. Journal of Neuroscience, 9. 3040-3057.

Rupniak, N. M. J., Duchnowski, M., Tye, S. J., Cook, G., \& Iversen, S. D. (1992). Failure of D-cycloserine to reverse cognitive disruption induced by scopolamine or phencyclidine in primates. Life Sciences, 50. 1959-1962.
Shapiro, M. L., \& Caramanos, Z. (1990). NMDA antagonist MK-801 impairs acquisition but not performance of spatial working and reference memory. Psychobiology, 18, 231-243.

ShaPIRo, M. L., \& O'ConNOR, C. (1992). N-methyl-D-aspartate receptor antagonist MK- 801 and spatial memory representation: Working memory is impaired in an unfamiliar environment but not in a familiar environment. Behavioral Neuroscience, 106, 604-612.

Tan, S., Kirk, R. C., Abraham, W. C., \& McNaughton, N. (1989). Effects of the NMDA antagonists CPP and MK-801 on delayed conditional discrimination. Psychopharmacology, 98, 556-560.

Tonkiss, J., \& Rawlins, J. N. P. (1991). The competitive NMDA antagonist APV, but not the noncompetitive antagonist MK-801, induces a delay-related impairment in spatial working memory in rats. Experimental Brain Research, 85, 349-358.

WATSON, J. E., \& BLAMPIED, N. M. (1989). Quantification of the effects of chlorpromazine on performance under delayed matching to sample in pigeons. Journal of the Experimental Analysis of Behavior, 51, 317-328.

WATSON, J. E., \& White, K. G. (1994). The effect of phenobarbital on rate of forgetting and proactive interference in delayed matching to sample. Psychobiology, 22, 31-36.

WHITE, K. G. (1985). Characteristics of forgetting functions in delayed matching to sample. Journal of the Experimental Analysis of Behavior, 44, 15-34.

WhITE, K. G., \& HARPER, D. N. (in press). Quantitative reanalysis of lesion effects on rate of forgetting in macaques. Behavioural Brain Research.

Wong, E. H. F., Kemp, J. A., Priestley, T., Knight, A. R., Woodruff, G. N., \& IVERSEN, L. L. (1986). The anticonvulsant MK-801 is a potent $N$-methyl-D-aspartate antagonist. Proceedings of the National Academy of Sciences, 83, 7104-7108.

(Manuscript received February 22, 1995; revision accepted for publication July 27,1995 .) 